\title{
ANÁLISE DAS APRESENTAÇÕES DE SLIDES NO ENSINO FUNDAMENTAL II E ENSINO MÉDIO
}

\author{
Bruna Raphaella F. De Andrade \\ UFPE \\ brunarf_andrade@hotmail.com \\ Renata Cadena \\ UFPE \\ renatx@gmail.com
Solange Galvão Coutinho
UFPE \\ solange.outinho@globo.com
}

\begin{abstract}
Resumo: As apresentações de slides são artefatos didáticos cada vez mais presentes no cotidiano escolar e são, principalmente, elaborados pelos professores. Este artigo descreve uma investigação em que se procurou conhecer detalhes sobre a produção e uso de apresentações digitais de slides para o ensino-aprendizagem. A pesquisa foi conduzida por meio de entrevistas com professores e funcionários de escolas e de análise de amostras de slideshows. Foram visitadas turmas do Ensino Fundamental II e Médio de 16 escolas recifenses com perfis diferenciados. Os resultados apontam para o crescente uso e importância desse artefato na dinâmica escolar, mas não a uma proporcional atenção à sua produção.
\end{abstract}

Palavras-chave: Apresentações de slides, Educação, Design da Informação

\section{INTRODUÇÃO}

As apresentações digitais de slides presentes no ambiente escolar têm "um caráter essencialmente didático, porque apresentam informações, conteúdos epistemológicos e propostas de atividade de disciplinas curriculares" (VIEIRA, 2011, p. 228). Neste artigo, abordamos uma investigação sobre o caráter gráfico desse artefato, que media relações de ensino-aprendizagem através de múltiplas mídias. Assim, buscamos conhecer as soluções de formatação utilizadas pelos docentes e as possíveis dificuldades na produção dos slideshows.

As apresentações de slides se popularizaram entre professores por qualidades como a facilidade de congregar linguagens diversas (imagens, esquemas, vídeos), a praticidade na exposição de conteúdos auxiliares e mesmo a possibilidade de 
reprodução em diversas turmas. Segundo Jamet (2009) as apresentações de slides são mais do que documentos multimídia; são também multimodais, logo, contém informações apreendidas pela visão e audição, de modo que o discurso oral deve estar relacionado ao que se observa visualmente. Elas são um típico exemplo de artefatos didáticos gerados pelos próprios docentes, assim como cartazes, fichas (Cadena, Coutinho \& Andrade, 2012) e informações na lousa, mas com o adicional de permitir, pela computação gráfica, a combinação com facilidade de recursos como fotos, ilustrações, efeitos de animação, cores e famílias tipográficas variadas.

Lai, Tsai \& Yu (2011) ressaltam as vantagens da utilização das apresentações de slides na aprendizagem: economia de tempo, planejamento de sequência e ritmo do conteúdo. No Brasil, a utilização de apresentações de slides na Educação têm se popularizado devido ao fomento no uso das TIC, com ações privadas e públicas, como a distribuição dos projetores Prolnfo desenvolvidos pelo Ministério da Educação.

Na pesquisa que descrevemos neste artigo, exploramos o uso e percepção por parte dos criadores (docentes ou outros funcionários) das apresentações digitais de slides em níveis escolares diferenciados (Ensino Fundamental II e Ensino Médio) e escolas com perfis diversos. Assim, o percurso metodológico contou, inicialmente, com entrevistas semiestruturadas com docentes e funcionários das escolas, visando compreender como se dá a criação e o uso das apresentações de slides. Esses mesmos docentes forneceram amostras das apresentações de slides para que pudessem ser analisadas segundo parâmetros balizados pelo Design da Informação. Através da análise, buscava-se observar a existência de padrões de organização da informação e também de possíveis problemas na configuração gráfica das mensagens.

Os parâmetros observados na análise das apresentações obtidas foram hierarquia da informação, escolha tipográfica, quantidade de slides, dentre outros. Uma contribuição importante foi a perspectiva de Twyman $(1979,2002)$, um pesquisador que tem uma contribuição essencial sobre produção de linguagem gráfica por não-especialistas em linguagem gráfica - ou seja, leigos que não são profissionais como cartógrafos, designes e ilustradores. A contribuição de Michael Twyman está na avaliação dos modos de simbolização da informação, que trata-se da forma que o originador optou para representar o dado: se por meio de texto e/ou dígitos (verbalnumérica), desenhos e fotografias (pictórica), ou tudo que não for verbal-numérico ou pictórico (esquemática). Categorizar as informações segundo tais critérios indica os modos preferidos pelos professores e se eles mantém a estrutura dos documentos tradicionais, como relatórios ou livros didáticos, ou se trazem outras formas de representação de informação, menos baseadas na linguagem verbal.

$O$ intuito dessa atenção aos slideshows se dá na perspectiva de que esses artefatos, à medida que são gráficos e criados pelos próprios docentes, contribuem para a formação visual dos estudantes, consumidores e geradores de linguagem gráfica. Também porque contém informações importantes, de cunho didático, de forma que têm um compromisso com a objetividade e com os significados. Assim, os resultados apresentados no decorrer desse artigo indicam aspectos facilitadores e dificuldades do uso, de modo a subsidiar os atores educacionais para a formatação de possíveis iniciativas formadoras, permitindo aos professores criar esses e outros artefatos gráficos de maneira satisfatória e instigante.

A defesa da inserção de conteúdos de design na formação de professores se dá justamente pelo seu cotidiano de formatador de objetos de cunho gráfico e pela 
observação da falta de disciplinas nas licenciaturas que preparem o professor para a comunicação através da linguagem gráfica. O projeto Ensina Design vem identificando, desde a sua primeira edição, as consequências na linguagem visual escolar decorrentes dessa lacuna das licenciaturas em objetos diversos (Coutinho \& Lopes, 2011), como murais e no uso da lousa. Assim, na segunda edição do projeto, temos empreendido investigações para a criação de iniciativas formadoras do olhar do professor, entendendo também as novas demandas e ferramentas relacionadas à crescente inserção de TICs (tecnologias da informação e comunicação) na escola.

\section{PERCURSO METODOLÓGICO}

Inicialmente, foram mapeadas as escolas que participariam da pesquisa, sendo selecionadas 16 instituições a partir do Ranking do ENEM 2011 segundo os seguintes critérios: as oito mais bem colocadas e as oito menos bem colocadas entre as privadas e públicas. Ao selecionar instituições com perfis diferenciados, buscamos compreender o uso das apresentações de slides em realidades distintas, considerando sempre o viés qualitativo da investigação empreendida.

Foram utilizados três métodos complementares para a coleta de dados: (a) observação exploratória da escola; (b) entrevistas semiestruturadas com diretores, funcionários e professores; e (c) coleta de amostras com professores.

Ao observar a escolas, buscou-se compreender a realidade e infraestrutura das mesmas, aspecto essencial para o uso das apresentações de slides, que necessitam de uma estrutura básica de instalação elétrica e de cabos de conexão e da presença de projetores digitais, os datashows.

Ao todo, 36 professores do Ensino Fundamental II (EF-II) e 34 do Ensino Médio (EM) que utilizam apresentações de slides foram entrevistados, sendo eles indicados pelos diretores e/ou coordenadores das instituições. Nas entrevistas, buscou-se compreender a rotina desses professores relativas ao uso dos softwares de criação de apresentações de slides, bem como sobre a aprendizagem no uso dos mesmos. Também foram avaliadas dificuldades e qualidades identificadas pelos docentes.

Sobre as amostras de slideshows recolhidas, elas totalizaram 16 em nível do Ensino Fundamental II e 17 do Ensino Médio e foram disponibilizados pelos próprios docentes via e-mail ou copiados em dispositivo digital (pendrive).

A tabela 1 relaciona os níveis escolares acompanhados na pesquisa e as disciplinas e os slides dos 70 professores entrevistados - vale ressaltar que há professores que ministram mais de uma disciplina. 
Tabela 1 - Relação entre nível escolar e disciplinas dos professores entrevistados e das apresentações de slides recolhidas.

\begin{tabular}{lllll}
\hline & \multicolumn{2}{l}{ Professores Entrevistados } & \multicolumn{2}{l}{ Apresentações de slides recolhidas } \\
\hline & Ensino Fundamental & Ensino Médio & Ensino Fundamental & Ensino Médio \\
\hline Português & 7 & 8 & 1 & 2 \\
\hline Matemática & 5 & 2 & 3 & 1 \\
\hline História & 7 & 6 & 2 & 2 \\
\hline Geografia & 6 & 4 & 5 & - \\
\hline Ciências & 6 & - & 3 & 1 \\
\hline Biologia & - & 4 & - & 1 \\
\hline Física & - & 2 & - & 1 \\
\hline Química & - & 2 & - & 2 \\
\hline Redação & 2 & 1 & - & 2 \\
\hline Literatura & 1 & 3 & - & 2 \\
\hline Inglês & 5 & 2 & 2 & - \\
\hline Espanhol & 1 & 3 & - & 1 \\
\hline Artes & 1 & 1 & - & 17 \\
\hline Sociologia & - & 2 & - & - \\
\hline Filosofia & - & 3 & - & \\
\hline Total & 36 & 34 & 16 & \\
\hline
\end{tabular}

Fonte: Elaborado pelas autoras, com base na pesquisa realizada.

As amostras de apresentações de slides recolhidas foram separadas por nível escolar, se Ensino Fundamental II ou Ensino Médio. Em seguida, os slideshows foram analisados tanto em seu aspecto macro, como todo, como no aspecto micro, ou seja, na formatação da linguagem gráfica presente nos slides.

Os critérios observados foram: (a) quantidade de slides para cada apresentação; (b) utilização de linguagens verbal, pictórica e/ou esquemática; (c) sobre a linguagem verbal, se utilizada com frases completas e/ou tópicos; (d) famílias tipográficas serifadas e não serifadas; (e) alinhamentos; e (f) ênfase hierárquica: tamanho, cor, peso, caixa alta, sublinhado e/ou efeito. Para cada um dos itens citados há recomendações de estudos sobre apresentações multimídia que trazem recomendações para a criação das mesmas, e sobre os quais comentaremos de maneira aplicada aos resultados encontrados, devido à curta extensão do formato de artigo.

\section{RESULTADOS E DISCUSSÕES}

Observamos que tanto na rede privada quanto na rede pública de Ensino, todos os professores consultados do Ensino Fundamental II e Ensino Médio possuem formação superior. Apesar da visita a instituições desses dois perfis, não observou-se uma significativa diferença na formatação dos slideshows - inclusive porque alguns docentes trabalham em instituições das duas naturezas.

Grande parte (ou a maioria) das escolas acompanhadas do EF-II e EM possuem salas de vídeo, laboratórios de informática e aparelhos de DataShow, (gráfico 1), o que indica a preocupação com a inserção de TICs, condizendo com o que também apontam os dados da pesquisa sobre o uso das Tecnologias de Informação e Comunicação nas Escolas Brasileiras do Comitê Gestor da Internet (CGI, 2014). 


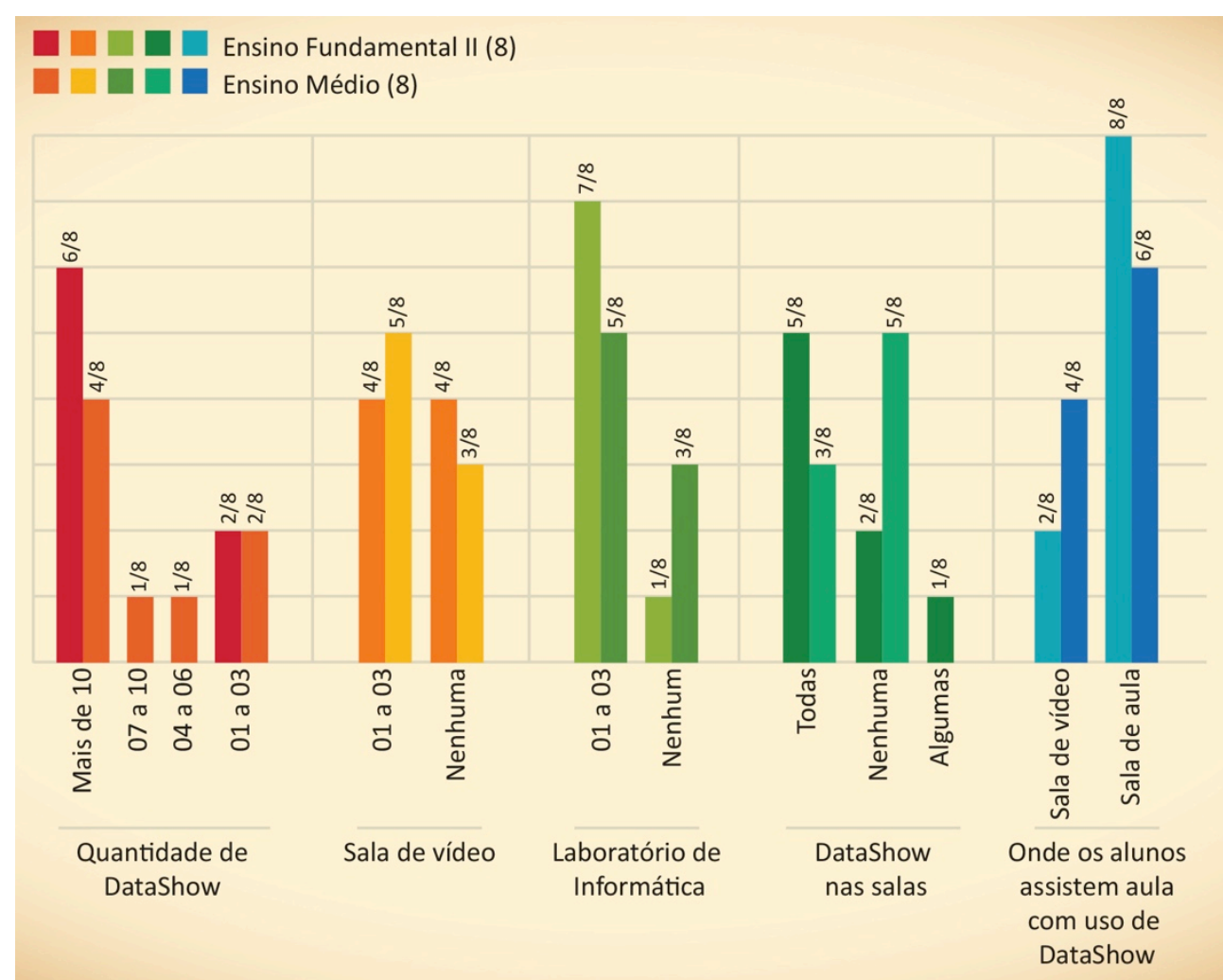

Gráfico 1 - Estrutura geral das escolas do Ensino Fundamental II e Ensino Médio, respectivamente. Fonte: Elaborado pelas autoras, com base na pesquisa realizada.

Como é possível observar no gráfico 1, os dados indicam uma grande inserção do DataShow no cotidiano escolar das escolas do Ensino Fundamental II, uma vez que a maioria delas possui o equipamento em todas as salas de aula e, também na maioria das vezes, os alunos assistem aulas nas salas que possui o DataShow. Em relação ao Ensino Médio, menos da metade das escolas acompanhadas possuem DataShow em todas as salas de forma que em metade das escolas do Ensino Médio os alunos assistem às aulas em que utilizam slides, também em salas de vídeo. Assim, provavelmente os professores do Ensino Médio das escolas acompanhadas fazem menos uso de apresentações de slides que os do Ensino Fundamental, uma vez que o acesso ao projetor é mais difícil - o que surpreende, uma vez que, em geral, acreditase que as tecnologias cheguem primeiro lugar para os níveis finais da educação.

\subsection{Das entrevistas com os professores e diretores}

Dos professores entrevistados no EF-II e EM, o gráfico 2 revela que a maioria utiliza o DataShow em aulas específicas; enquanto que, uma menor parte utiliza o DataShow em todas as aulas. Eles utilizam apresentações de slides principalmente para exposição de conteúdos e/ou como complementação de conteúdos com outras mídias, como vídeos e imagens.

É perceptível que a maioria dos professores do Ensino Fundamental II e Ensino Médio apontaram que muitos dos seus alunos ficam mais motivados nas aulas em que se usam os slideshows, dados indicados no gráfico 2. Um professor de escola pública do Ensino Fundamental II explicou que era pela "novidade" e um professor de escola privada relatou que é por conta do "estilo do professor que motiva". De acordo com um professor de escola pública do Ensino Médio "o visual chama a atenção", porém, outro professor de escola pública apontou que apesar de a maioria de seus alunos ficar 
mais motivada quando ele usa apresentações de slides, ele "não pode usar sempre porque fica enfadonho". Essa ideia está em consonância com Burke \& James (2008), que ressaltam o que chamam de "efeito novidade" dos slideshows, atrelando a sua eficácia pedagógica aos primeiros usos dessa ferramenta com uma turma, de forma que o apelo tende a diminuir com o tempo. Assim, acredita-se que utilizando as apresentações de slides com cautela e para situações favoráveis, em que o recurso multimídia é enriquecedor para o conteúdo, o efeito motivador desse recurso tende a ser preservado.

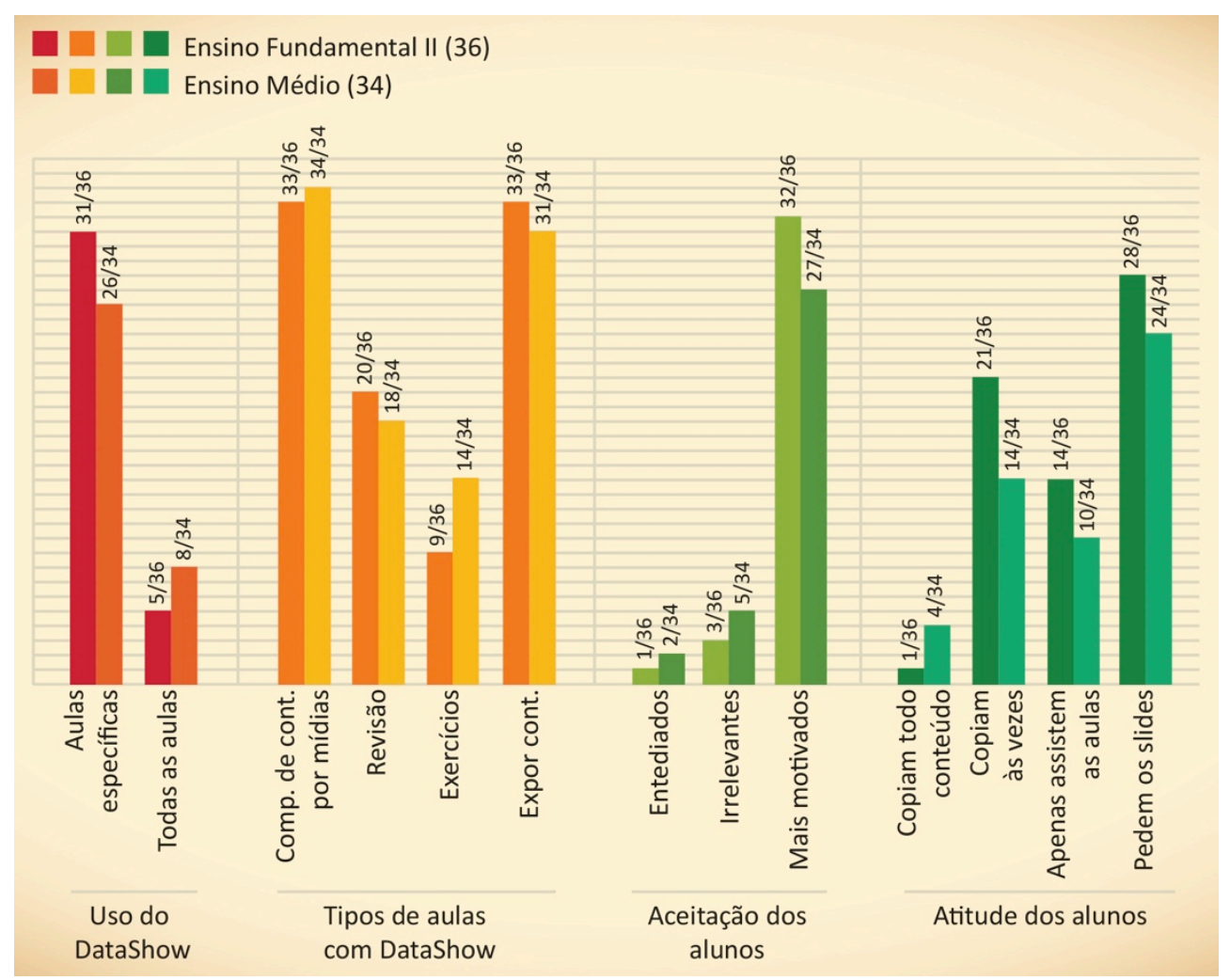

Gráfico 2 - Das entrevistas, Ensino Fundamental II e Ensino Médio, respectivamente.

Fonte: Elaborado pelas autoras, com base na pesquisa realizada.

É mais comum, tanto para o Ensino Fundamental II quanto para o Ensino Médio, os alunos anotarem às vezes algum conteúdo que acham relevante dos slideshows, (gráfico 2). Essa atitude poderia ser diminuída se fossem distribuídos panfletos com resumos do conteúdo para evitar que o aluno se disperse anotando e apenas foque nas apresentações, conforme sugerem especialistas como Doumont (2005) e Mollerup (2011).

Por último e reforçando o que aconselham esses autores sobre a distribuição de panfletos ou material complementar, o gráfico 2 revela que a maioria dos professores do EF-II e EM afirmam que muitos alunos pedem para que eles disponibilizem as apresentações de slides via e-mail ou copiado no pendrive; e um professor do Ensino Fundamental II ainda apontou que os alunos também fotografam slides que consideram importantes.

Todos os professores consultados do Ensino Fundamental II e a maioria do Ensino Médio produzem suas próprias apresentações de slides, além de alguns destes também utilizarem slideshows de outras fontes - como CDs de livros didáticos, de 
outros professores, do Professor Autor (programa de apoio pedagógico da Secretaria de Educação de Pernambuco) e/ou de ex-estagiário (gráfico 3).

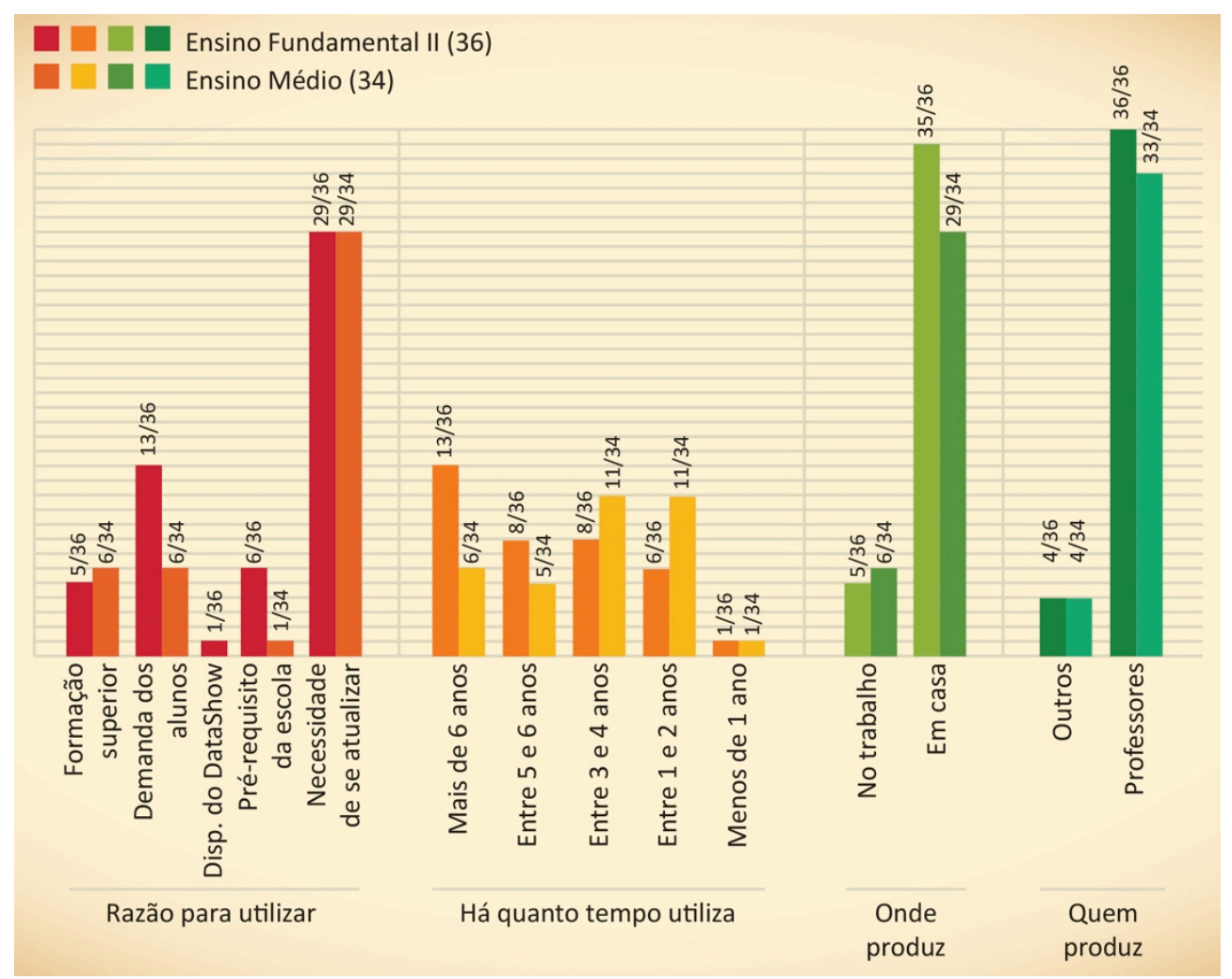

Gráfico 3 - Das entrevistas, Ensino Fundamental II e Ensino Médio, respectivamente.

Fonte: Elaborado pelas autoras, com base na pesquisa realizada.

A pesquisa também revela há quanto tempo os professores utilizam slideshows, variando entre menos de um ano e mais de seis anos; e que começaram a utilizar por necessidade de se atualizar no ambiente tecnológico o que mostra que estão atentos (e são cobrados para estar) às práticas didáticas vigentes, mas também que não foi uma necessidade inerente às suas práticas didáticas, mas relacionada a demandas externas (dados apontados no gráfico 3).

O software mais utilizado pelos professores consultados é o PowerPoint, incluindo versões similares, como exemplo o BrOffice (dados apontados no gráfico 4). É válido ressaltar que muitos professores não tiveram uma formação para a utilização dos softwares de produção do artefato 'slide', um professor de escola pública do Ensino Fundamental II, inclusive apontou que recebe "dicas" dos próprios alunos. Quanto à maneira com que desenvolvem o conteúdo dos slides, a maioria dos professores do EF-II e EM elaboram os slides à medida que desenvolve o projeto, ou seja, elabora direto no software, sem rascunhos ou planejamentos anteriores. Além de alguns professores entrevistados, de ambos universos, também fazerem download de apresentações prontas da internet e editarem algum conteúdo que não esteja adequado à sua turma (gráfico 4). 


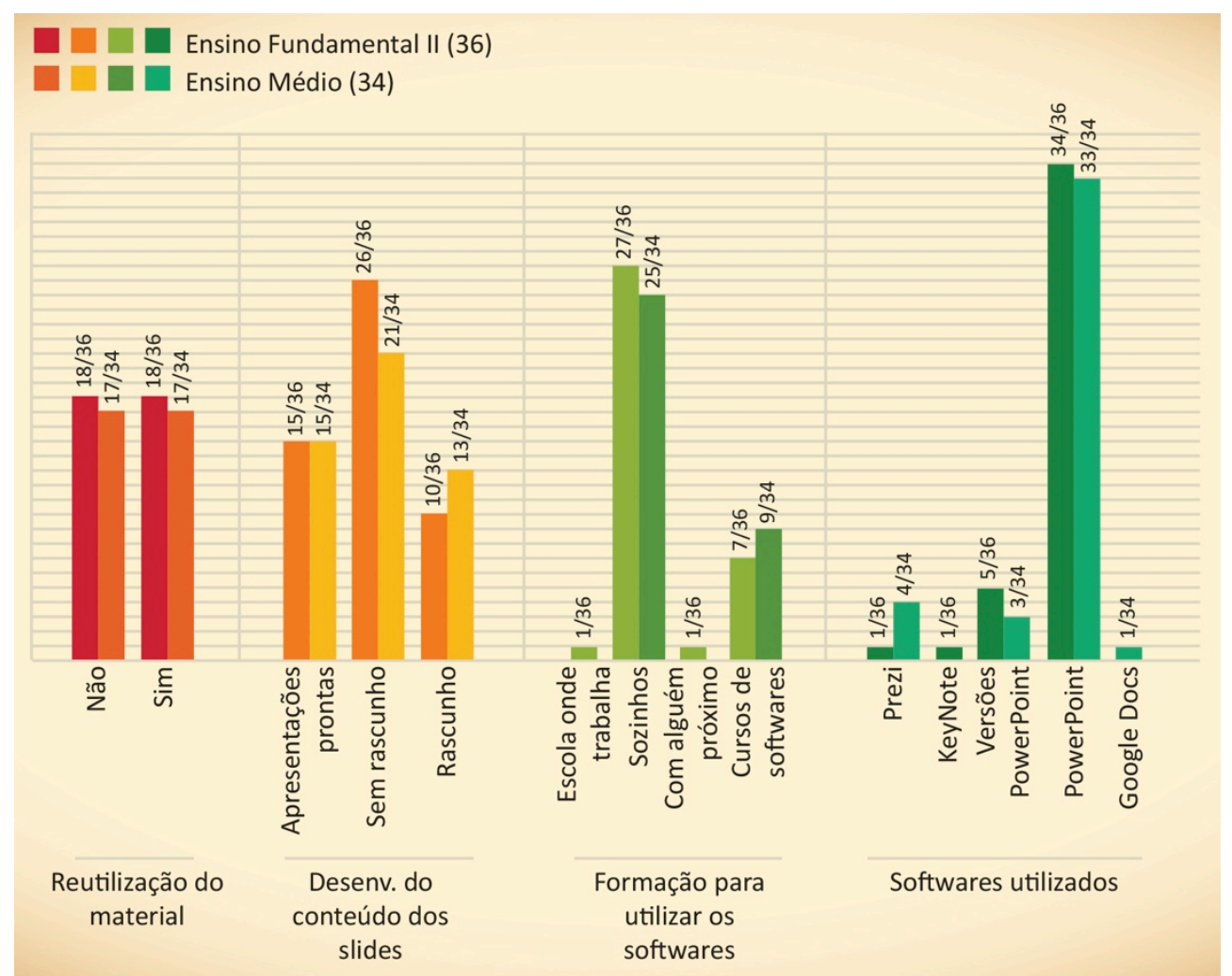

Gráfico 4 - Das entrevistas, Ensino Fundamental II e Ensino Médio, respectivamente.

Fonte: Elaborado pelas autoras, com base na pesquisa realizada.

Observou-se também que metade dos professores, tanto do EF-II e EM, reutiliza o material de uma série para outra se for adequado para os níveis escolares.

\subsection{Da análise dos slideshows}

Foram recolhidas 16 apresentações de slides do Ensino Fundamental II e 17 do Ensino Médio. É importante esclarecer que para a análise dos slideshows foi considerada como unidade informacional a apresentação de slides como um todo, ou seja, o conjunto de todos os slides, e não um slide para cada apresentação. Contudo, nas apresentações de slides não foi considerado um item predominante, uma vez que em um slideshow pode ter slides completamente distintos; mas foram listados todos os dados encontrados pertinentes à pesquisa em cada slide dos slideshows. A quantidade de slides de cada apresentação é bem diversa, como mostra o gráfico 5 , e predominam as que têm menos slides.

Mesmo sendo, segundo os professores entrevistados do Ensino Fundamental II, o PowerPoint o software mais utilizado (gráfico 4), a metade das amostras recolhidas apresentaram outros templates (modelos gráficos) originários desse software, de forma que eram produzidos ou não pelos professores; abordagem diferente do Ensino Médio, em que se usa principalmente templates do PowerPoint (figura 1, gráfico 5). 


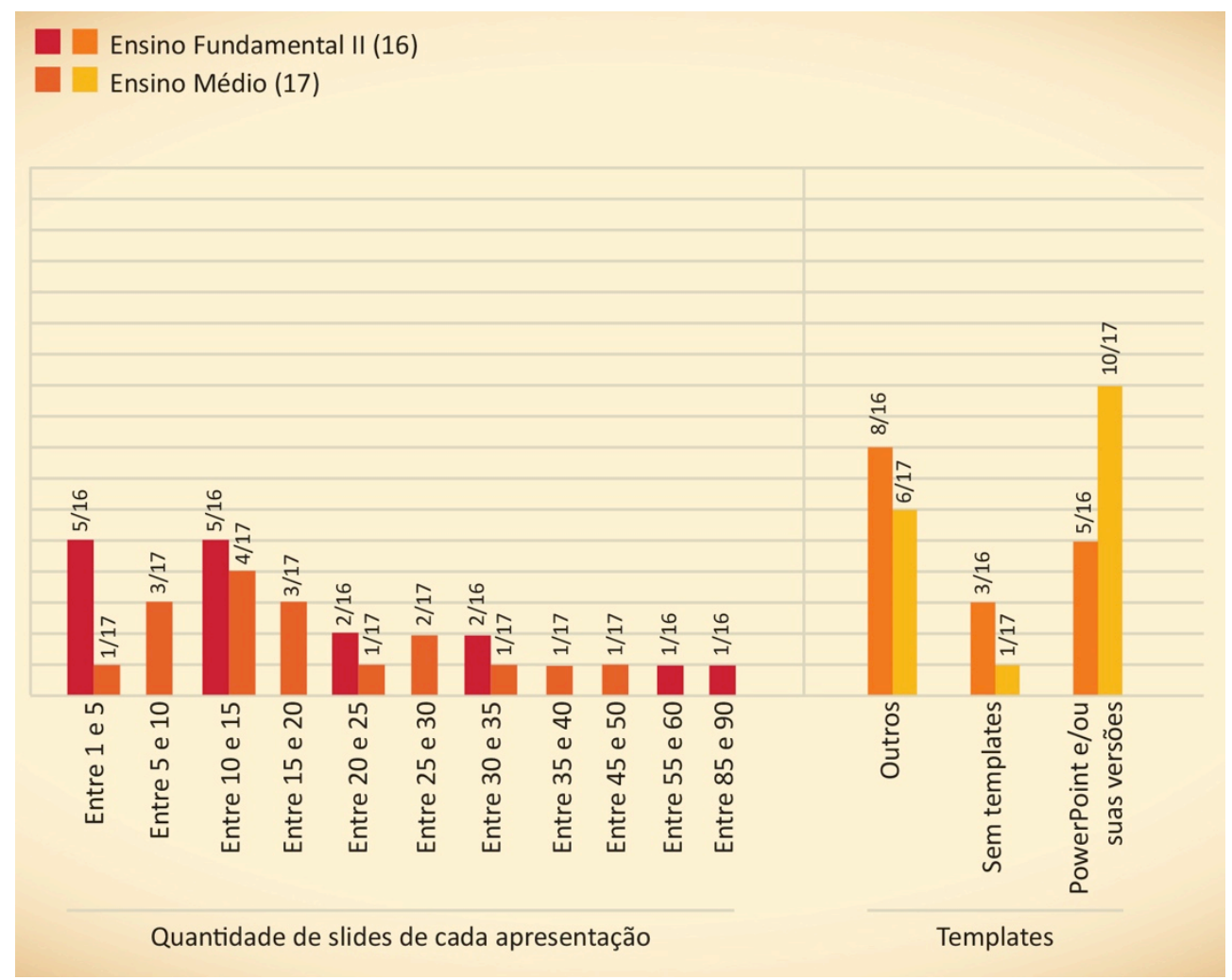

Gráfico 5 - Das entrevistas, Ensino Fundamental II e Ensino Médio, respectivamente. Fonte: Elaborado pelas autoras, com base na pesquisa realizada.

Para a análise do modo de simbolização não foram considerados os templates, mas os conteúdos didáticos das apresentações de slides, sendo possível considerar mais de um modo de simbolização. A maioria das apresentações de slides do Ensino Fundamental II apresenta como modo de simbolização a Linguagem Pictórica (figura 2); muitos também apresentam a Linguagem Verbal; e/ou a metade também apresenta a Linguagem Esquemática (gráfico 6). É válido ressaltar que as imagens têm efeitos positivos na memorização e compreensão, sobretudo para os estudantes pouco experientes, segundo Jamet (2009); sendo assim, a maioria das apresentações do Ensino Fundamental II revelam bons indícios ao utilizarem a Linguagem Pictórica com maior frequência. Já a maioria das apresentações de slides do Ensino Médio diferencia bastante quando comparado às apresentações de slides do Ensino Fundamental II, uma vez que apresenta como modo de simbolização dominante a Linguagem Verbal; algumas também apresentam a Linguagem Pictórica e/ou a Linguagem Esquemática.
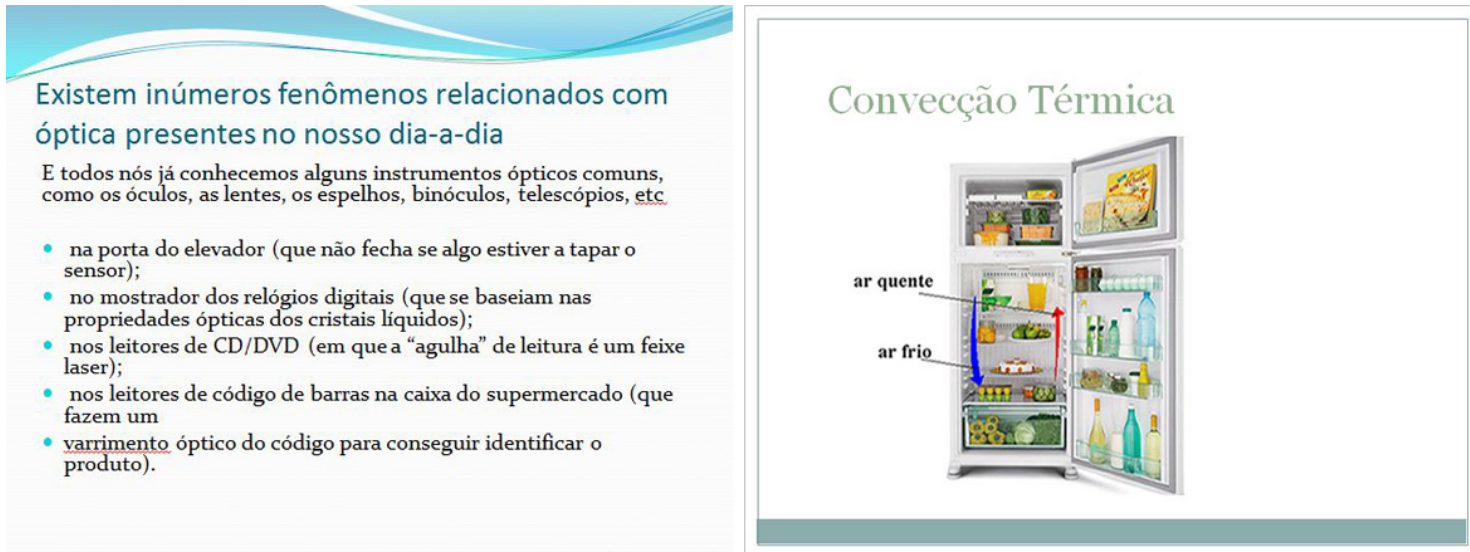
Figuras 1 e 2 - Física, Ensino Médio e Ciências, Ensino Fundamental II; respectivamente.

Fonte: Disponibilizado por um professor de Física, Ensino Médio e por um professor de Ciências, Ensino Fundamental II; respectivamente.

Sobre a Linguagem Verbal, predominam os textos corridos nos slides do EF-II e EM (figura 3, gráfico 6); o que não condiz com a defesa de Doumont (2005), onde reforça que o foco deve estar na mensagem e não o detalhamento dela e, desta forma, os slides devem ter a menor quantidade possível de texto.

A maioria dos textos dos slideshows analisados de uma maneira geral utilizam famílias tipográficas sem serifa (figura 3, gráfico 6), condizendo com o que defende Jamet (2009), para quem as fontes sem serifas são mais legíveis - e agradaram mais aos estudantes que ele investigou.

O alinhamento à esquerda é mais comum nos slides do Ensino Fundamental II, enquanto que nos slides do Ensino Médio, é mais comum o alinhamento justificado (figura 3, gráfico 6). É válido ressaltar que o alinhamento à esquerda é mais recomendável porque os textos justificados forçam a quebra arbitrária das palavras e a um espacejamento forçado entre as letras do texto.

Quanto à hierarquia informacional, nos slides do Ensino Fundamental II foi mais comum a ênfase pelo tamanho das letras; e no Ensino Médio pelo tamanho das letras e pela variação de cores (figura 4, gráfico 6). Interessante destacar que estes resultados não condizem com estudos de Tinker (1965), os quais sugerem que a variável tipográfica mais legível de conferir ênfase em um texto é por meio do uso negrito.

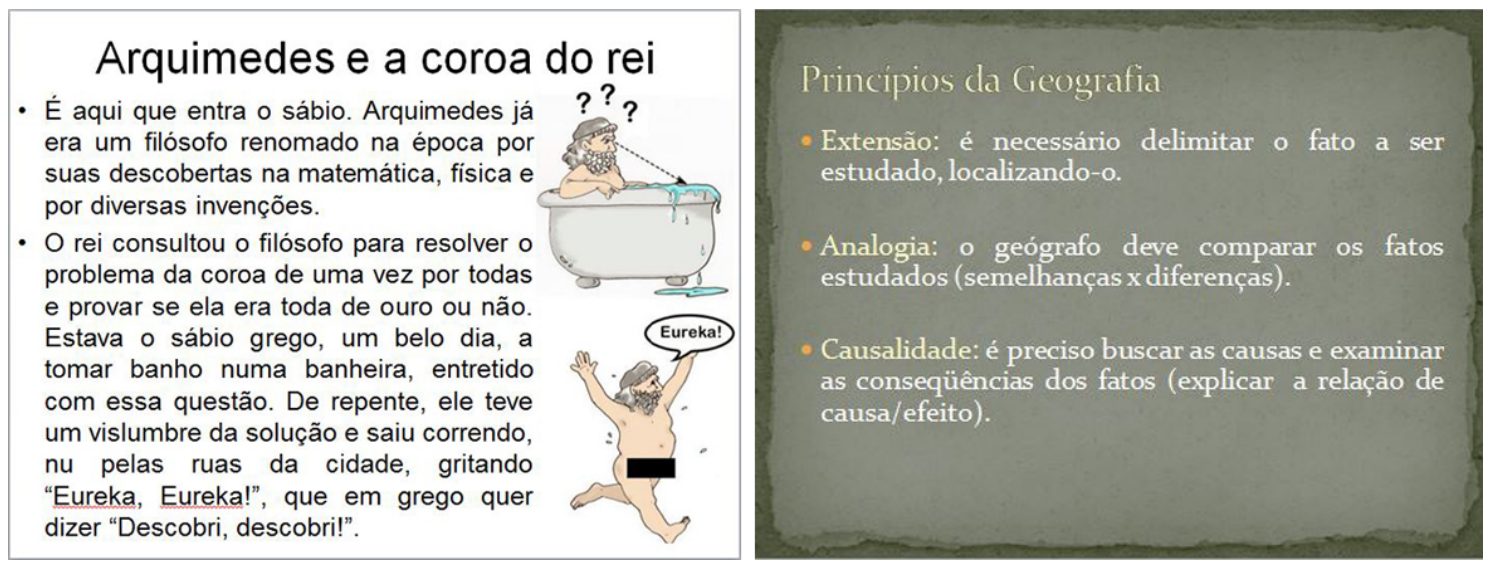

Figuras 3 e 4 - Química e Geografia, ambos os slides Ensino Médio; respectivamente.

Fonte: Disponibilizado por um professor de Química e por um professor de Geografia, Ensino Médio; respectivamente. 


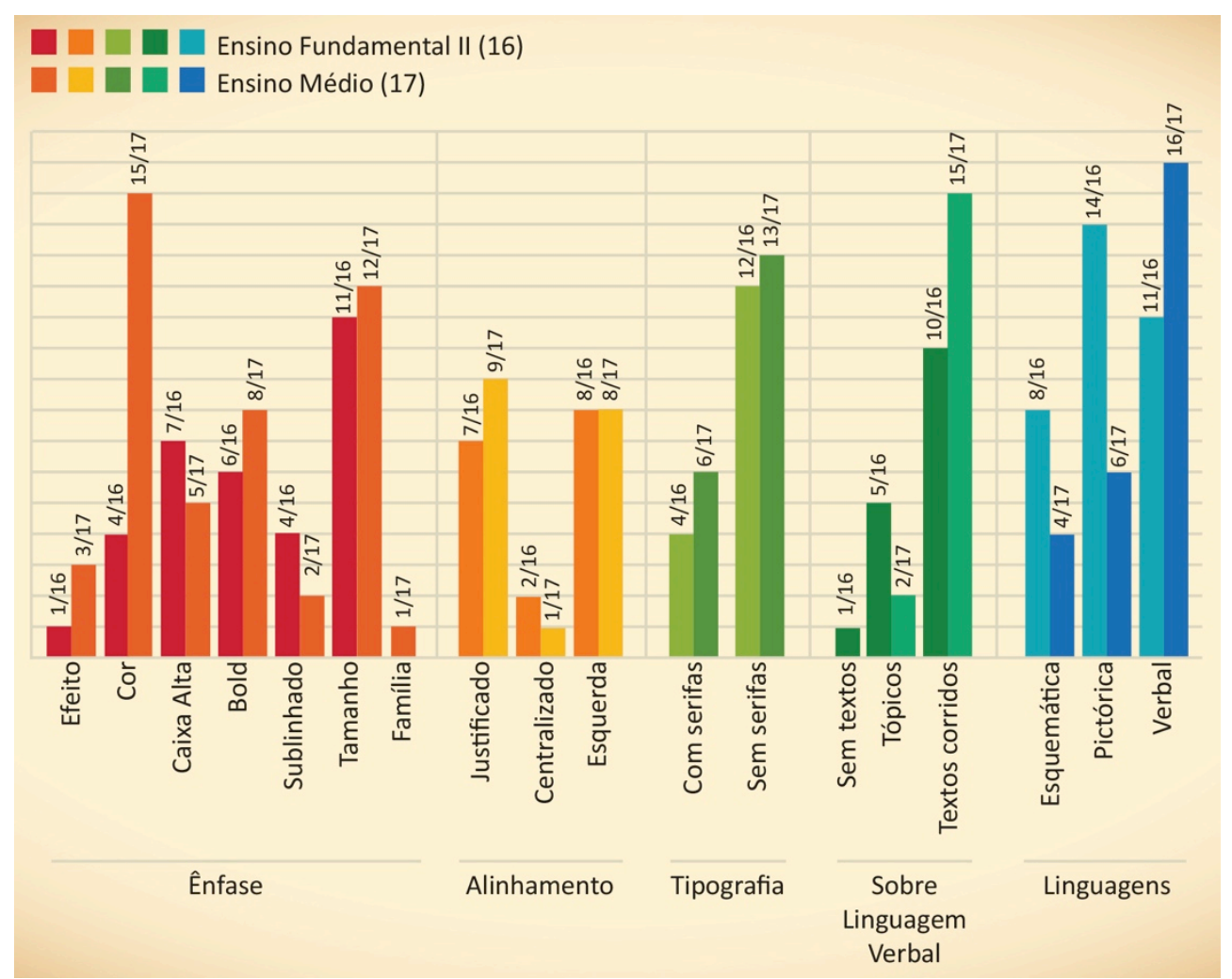

Gráfico 6 - Dos slides, Ensino Fundamental Il e Ensino Médio, respectivamente. Fonte: Elaborado pelas autoras, com base na pesquisa realizada.

\section{CONCLUSÃO}

Neste artigo, foram analisadas entrevistas feitas com professores de Ensino Fundamental II e Ensino Médio sobre a elaboração, formatação e uso das apresentações de slides. Estes artefatos, assim como tantos outros presentes no cotidiano escolar, servem como mediadores do conhecimento e da aprendizagem.

É válido destacar que, apesar dos professores não terem formação específica para gerar slideshows adequados ao uso escolar, pode-se encontrar alguns pontos positivos como o uso recorrente de famílias tipográficas sem serifas - como já citado neste artigo, Jamet (2009) defende que elas são mais legíveis e agradam mais no contexto dos slides. E o recorrente uso da Linguagem Pictórica na maioria dos slides do Ensino Fundamental II. Contudo, a falta de formação específica não permite que professores tenham segurança sobre as decisões organizacionais que tomam, tal fato é perceptível no uso da Linguagem Verbal que predominam os textos corridos, apesar de os slideshows serem proeminentemente multimídia. Ainda pode ser percebido o número elevado de slides em algumas apresentações, chegando a 86 em uma das amostras.

Foi observado que muitos dos índices da pesquisa do Ensino Fundamental II se equiparam aos índices do Ensino Médio. Essa observação demonstra que os professores do Ensino Fundamental II e os professores do Ensino Médio não necessariamente diferenciam suas produções de acordo com o nível escolar, apesar de atenderem a usuários com interesses geralmente bastante distintos (pré adolescentes e pré-vestibulandos, por exemplo), o que pode colocar em risco o potencial informativo, educativo e sensibilizador das apresentações de slides.

Logo, os indícios encontrados nesta pesquisa - da não adequação dos slideshows - podem contribuir para que a motivação e o interesse dos alunos sejam 
facilmente potencializados, segundo Vieira (2011), as apresentações de slides "constituem recursos que despertam o interesse dos leitores para o tema e atraem a atenção da audiência para a aula ministrada pelo professor", ideia reforçada pela maioria dos entrevistados.

Esta pesquisa aponta para o fato de que os slideshows e outras TICs, como tablets e lousas digitais, estão cada vez mais presentes no cotidiano escolar, logo, os professores têm que lidar com ferramentas novas de produção gráfica, com novas possibilidades de formatação dos conteúdos escolares. Os resultados das entrevistas mostram que os professores acreditam nesse potencial.

Com isso, abre-se espaço para discussões sobre a parceria entre os campos de Design e da Educação, especificamente da necessidade de inserir conteúdos de Design Gráfico e Design da Informação na formação dos professores. Acreditamos que tal formação pode equipar os professores com conhecimentos e habilidades para tornar a escola um ambiente mais integrado com as novas linguagens correntes, como as apresentações de slides, melhorando a representação de conteúdos e motivando os alunos.

\section{REFERÊNCIAS}

BURKE, Lisa A.; JAMES, Karen E. PowerPoint-based lectures in business education: an empirical investigation of student-perceived novelty and effectiveness. Business Comunication Quarterly, 2008, v.71(3): 277-296.

CADENA, Renata; COUTINHO, Solange; ANDRADE, Bruna. A linguagem gráfica em artefatos educacionais gerados com ferramentas de TIC. InfoDesign, 2012, v.9(1): 3345.

COUTINHO, Solange; LOPES, Maria Teresa. Design para educação: uma possível contribuição para o ensino fundamental brasileiro. $\mathbf{O}$ papel social do design gráfico: história, conceitos \& atuação profissional. São Paulo: Editora Senac, 2011

CGI. TIC Educação 2012 - Professores. CETIC.br. Disponível na internet por http em: < www.cetic.br/educacao/2012/professores/C1>. Acesso em 27 mar 2014.

DOUMONT, Jean-Luc. The cognitive style of PowerPoint: Slides are not all evil. Technical Communication, 2005, v.52(1): 64-70.

JAMET, Éric. Peut-on concevoir des documents électroniques plus efficacies? L'exemple des diaporamas. Revue européene de psychologie apliquée, 2009, v.58: 185-198.

LAI, Yen-Shou; TSAI, Hung-Hung; YU, Pao-Ta. Integrating Annotations into a Dual-slide PowerPoint Presentation for Classoroom Learning. In: Educacional Technoloy \& Society, 2001, v.14(2): 43-57.

MOLLERUP, Per. PowerNotes: slide presentations reconsidered. Melboume: IIID International Institute for Information Design. Universidade de Tecnologia de Swinburne, 2011. Disponível em <http://hdl.handle.net/1959.3/191214> Acessado em: 7 jun. 2012.

TINKER, Miles A. Bases for Effective Reading. Minneapolis: University of Minnesota Press, 1965. 
TWYMAN, Michael L. A schema for the study of graphic language. In: Paul A. Kolers, Merald E. Wrolstad \& Herman Bouma (Org.). Processing of visible language. Nova York \& Londres: Plenum Press, 1979, v.1: 117-150.

Further thoughts on a schema for describing graphic language. Proceedings of the 1st International Conference on typography \& Visual Communication, History, Theory, Education. Thessaloniki, Grécia, 2002. p. 329-350.

VIEIRA, Ana Regina Ferraz. Retórica e multimodalidade do PowerPoint educativo. Tese de doutorado não publicada. Departamento de Letras, UFPE, Recife - Brasil, 2011. 